University of Nebraska - Lincoln

DigitalCommons@University of Nebraska - Lincoln

U.S. National Park Service Publications and

Papers

National Park Service

$1-2-2020$

\title{
Predicting livestock depredation risk by African lions (Panthera leo) in a multi-use area of northern Tanzania
}

\author{
K. Beattie \\ University of Connecticut, Storrs \& Northland College, kristen.beattie@uconn.edu \\ E.R. Olson \\ Northland College \\ B. Kissui \\ Center for Wildlife Management Studies
}

A. Kirschbaum

Great Lakes Inventory and Monitoring Network

C. Kiffner

Center for Wildlife Management Studies

Follow this and additional works at: https://digitalcommons.unl.edu/natlpark

Part of the Environmental Education Commons, Environmental Policy Commons, Environmental Studies Commons, Fire Science and Firefighting Commons, Leisure Studies Commons, Natural Resource Economics Commons, Natural Resources Management and Policy Commons, Nature and Society Relations Commons, Other Environmental Sciences Commons, Physical and Environmental Geography Commons, Public Administration Commons, and the Recreation, Parks and Tourism Administration Commons

Beattie, K.; Olson, E.R.; Kissui, B.; Kirschbaum, A.; and Kiffner, C., "Predicting livestock depredation risk by African lions (Panthera leo) in a multi-use area of northern Tanzania" (2020). U.S. National Park Service Publications and Papers. 196.

https://digitalcommons.unl.edu/natlpark/196

This Article is brought to you for free and open access by the National Park Service at DigitalCommons@University of Nebraska - Lincoln. It has been accepted for inclusion in U.S. National Park Service Publications and Papers by an authorized administrator of DigitalCommons@University of Nebraska - Lincoln. 


\title{
Predicting livestock depredation risk by African lions (Panthera leo) in a multi-use area of northern Tanzania
}

\author{
K. Beattie ${ }^{1,2}$ (D) E. R. Olson ${ }^{2}$ - B. Kissui ${ }^{3}$ - A. Kirschbaum ${ }^{4}$ - C. Kiffner ${ }^{3}$
}

Received: 30 November 2018 /Revised: 5 December 2019 / Accepted: 14 December 2019 / Published online: 2 January 2020

(C) Springer-Verlag GmbH Germany, part of Springer Nature 2020

U.S. government works are not subject to copyright.

\begin{abstract}
Human-wildlife conflicts, especially those involving large carnivores, are of global conservation and livelihood concern and require effective and locally-adapted prevention measures. Risk of lion attack on livestock (i.e., depredation) may vary seasonally and may be associated with variation in wild prey abundance or landscape characteristics. To test these competing hypotheses, we used a resource selection approach, and determined whether prey catchability (indicated by geo-spatial variables), or prey availability (indicated by modeled abundance recorded via camera traps) explained spatial and seasonal variation in livestock depredation risk by African lions on Manyara Ranch Conservancy, a multi-use area in northern Tanzania. Seasonal variation in vegetative productivity and proximity to surface water appeared to be strong predictors of livestock depredation risk. Correlates for depredation risk were different between wet and dry seasons. During the dry season, depredation risk was positively correlated with vegetative productivity, whereas depredation risk during the wet season was highest near livestock enclosures (bomas). During both seasons, depredation risk was high closer to surface water. Landscape-driven risk maps were created to identify low risk areas that may be compatible with livestock grazing. Our results on depredation risk by lions are similar to other studies in protected areas and suggest that both prey catchability and prey availability are instrumental in predicting kill sites of lions. To facilitate lion and livestock coexistence in multi-use areas of Africa, we recommend minimizing spatiotemporal overlap between livestock and abundant wild prey by developing alternative livestock water and feeding locations and increasing caution near surface water areas.
\end{abstract}

Keywords Carnivore conservation $\cdot$ Depredation $\cdot$ Human-wildlife conflict $\cdot$ Panthera leo $\cdot$ Risk map $\cdot$ Seasonal variation

\section{Introduction}

Human-wildlife conflict is a global conservation and livelihood issue, especially when conflicts involve large carnivores

Electronic supplementary material The online version of this article (https://doi.org/10.1007/s10344-019-1348-5) contains supplementary material, which is available to authorized users.

K. Beattie

kristen.beattie@uconn.edu

1 University of Connecticut, Storrs, CT, USA

2 Northland College, 1411 Ellis Avenue, Ashland, WI, USA

3 School for Field Studies, Center for Wildlife Management Studies, PO Box 304, Karatu, Tanzania

4 National Park Service, Great Lakes Inventory and Monitoring Network, 2800 Lake Shore Drive East, Ashland, WI, USA
(Ripple et al. 2014; Treves and Karanth 2003; Madden 2004). Competition over food, exacerbated by spatiotemporal overlap in habitat use can lead to conflicts with carnivores (Treves and Karanth 2003; Inskip and Zimmermann 2009). Large carnivores may attack domestic animals, compete for wild prey, or, in rare cases, attack humans (Kruuk 2002; Woodroffe et al. 2005; Olson et al. 2015a; Kissui 2008; Behdarvand and Kaboli 2015; Packer et al. 2005; Madden 2004). Most large carnivore populations are in decline globally, in large part due to ineffective non-lethal conflict prevention and mitigation which often leads to lethal control or retaliatory killing of carnivores (Ripple et al. 2014). Carnivore attacks on domestic animals (i.e., depredations) can have significant economic impacts (Woodroffe et al. 2005; Bommel et al. 2007; Mishra et al. 2003; Patterson et al. 2004; Kissui 2008) and can be traumatic or foster negative attitudes toward carnivores if poorly managed (Fritts and Paul 1989; Olson et al. 2015b; Bencin et al. 2016). Without effective and efficient conflict prevention and mitigation efforts, local people perceive carnivores as a threat or a 
cause of economic loss, and may eventually turn to retaliatory killing (Kissui 2008; Sundararaj et al. 2012; Hazzah et al. 2014; Lyngdoh et al. 2014; Olson et al. 2015b; Mishra et al. 2003; Inskip and Zimmermann 2009). Globally, retaliatory killings are one of the leading causes of large carnivore population declines (Inskip and Zimmermann 2009; Nowell and Jackson 1996; Ripple et al. 2014).

African lions Panthera leo (hereafter: lions) are particularly prone to retaliatory killing, since (1) cattle Bos taurus (a highly valued asset in the predominant pastoral communities that are dominating Africa's savannas) are within their preferred prey weight range, (2) lions usually defend their prey and are thus highly susceptible to retaliatory killing, and (3) ritual killings of lions (which may be additionally provoked by livestock depredation events) are part of many pastoralists cultures (Chellam 1993; Singh and Kamboj 1996; Patterson et al. 2004; Woodroffe et al. 2005; Hayward and Kerley 2006; Ikanda and Packer 2008; Kissui 2008; Hazzah et al. 2009; Meena et al. 2011; Sundararaj et al. 2012; Goldman et al. 2013). For example, in Cameroon, the lion population of Waza National Park declined by $50 \%$, mainly due to the conflicts with surrounding pastoralists (Henschel 2006) and human-lion conflict and the associated retaliatory killing has been suggested to be one of the key drivers associated with the recent sharp declines of lion range and population sizes across Africa (Riggio et al. 2013; Bauer et al. 2015). Therefore, preventing and mitigating human-lion conflict is a critical step in the protection of lion populations (Bommel et al. 2007; Hazzah et al. 2014). To effectively prevent and mitigate human-large carnivore conflict, conservationists must understand the factors that influence people to retaliate and kill carnivores (Musiani et al. 2005; Bommel et al. 2007; Hazzah et al. 2014; Behdarvand and Kaboli 2015; Olson et al. 2015a).

Several variables have been found to be associated with human-large carnivore conflicts. For example, many researchers suggest that large carnivore attacks on livestock are influenced by the abundance of wild prey (Meriggi and Lovari 1996; Mizutani 1999; Mishra 2001; Mishra et al. 2001; Stoddart et al. 2001; Polisar et al. 2003; Musiani et al. 2005; Kolowski and Holekamp 2005; Woodroffe et al. 2005; Azevedo 2008; Odden et al. 2008). In areas where native wildlife is depleted and replaced by livestock, carnivores are likely to encounter livestock more frequently and may switch to an alternative, livestock prey source (Murdoch 1969; Meriggi and Lovari 1996; Stoddart et al. 2001; Patterson et al. 2004; Azevedo 2008; Sundararaj et al. 2012, Khorozyan et al. 2015). In addition to high livestock densities, livestock species also tend to lack the anti-predator behaviors of their wild counterparts, making them particularly vulnerable as a prey source (Price 1984; Chellam 1993; Singh and Kamboj 1996; Nowell and Jackson 1996; Price 2002; Diamond 2002; Patterson et al. 2004; Meena et al. 2011; Sundararaj et al. 2012).
An alternative hypothesis to the 'prey availability' hypothesis is that particular spatial features facilitate 'prey catchability' by large carnivores, which may be particularly relevant for lions that typically ambush their prey (Schaller 1972; Hopcraft et al. 2005). In savanna ecosystems, both prey distribution and catchability may vary between seasons (Hopcraft et al. 2005; Kuiper et al. 2015). Wild prey distribution during the dry season is usually constrained to areas near water resources (Owen-Smith and Mills 2008; Davidson et al. 2012) and lions often kill prey closer to water resources (Hopcraft et al. 2005; Valeix et al. 2009; Davidson et al. 2012). During the wet season, available surface water resources are plentiful and wild prey disperse throughout the landscape (Patterson et al. 2004). However, there are contrasting patterns with respect to seasonal patterns of livestock depredation (i.e., killing of livestock) by lions. Some studies report an increase in lion attacks on livestock during the dry season in areas near water resources where there was ample vegetative cover (Butler 2000; Kays and Patterson 2002), whereas other studies reported an increase in lion attacks on livestock during the wetter months (Kolowski and Holekamp 2005, Kuiper et al. 2015; Koziarski et al. 2016).

To identify whether livestock abundance, wildlife abundance, or spatial features that may affect prey catchability are related to livestock depredation risk by lions, we used a resource selection approach to predict seasonal livestock depredation risk in a multiple use area of northern Tanzania. We hypothesized that livestock attack sites were more common in areas near surface water resources and with high NDVI values as resources valued by both livestock and wild prey overlap (i.e., water and palatable vegetation) and that livestock site selection of lions were mediated by seasons.

\section{Materials and methods}

\section{Study area}

We conducted this study in Manyara Ranch Conservancy, a multiple-use area that support wildlife conservation and pastoralist lifestyles of adjacent communities (The Tanzania Land Conservation Trust 2011; Fig. 1). Manyara Ranch is located in the Tarangire-Manyara Ecosystem and central for the seasonal migration of ungulates (Kiffner et al. 2016). The semi-arid ecosystem has three main seasons: the long rains from February to May, the dry season from June to October, and the short rains from November to December (Pittiglio et al. 2012). Rainfall varies throughout the year, ranging from 415 to $844 \mathrm{~mm}$ per year (Mwalyosi 1992, Fig. 2). The ranch encompasses ca. $182 \mathrm{~km}^{2}$, and the vegetation is characterized by Acacia-Commiphora savannah and grasslands. Surface water is provided by several dams and by the Makuyuni River that bisects the area (Kiffner et al. 


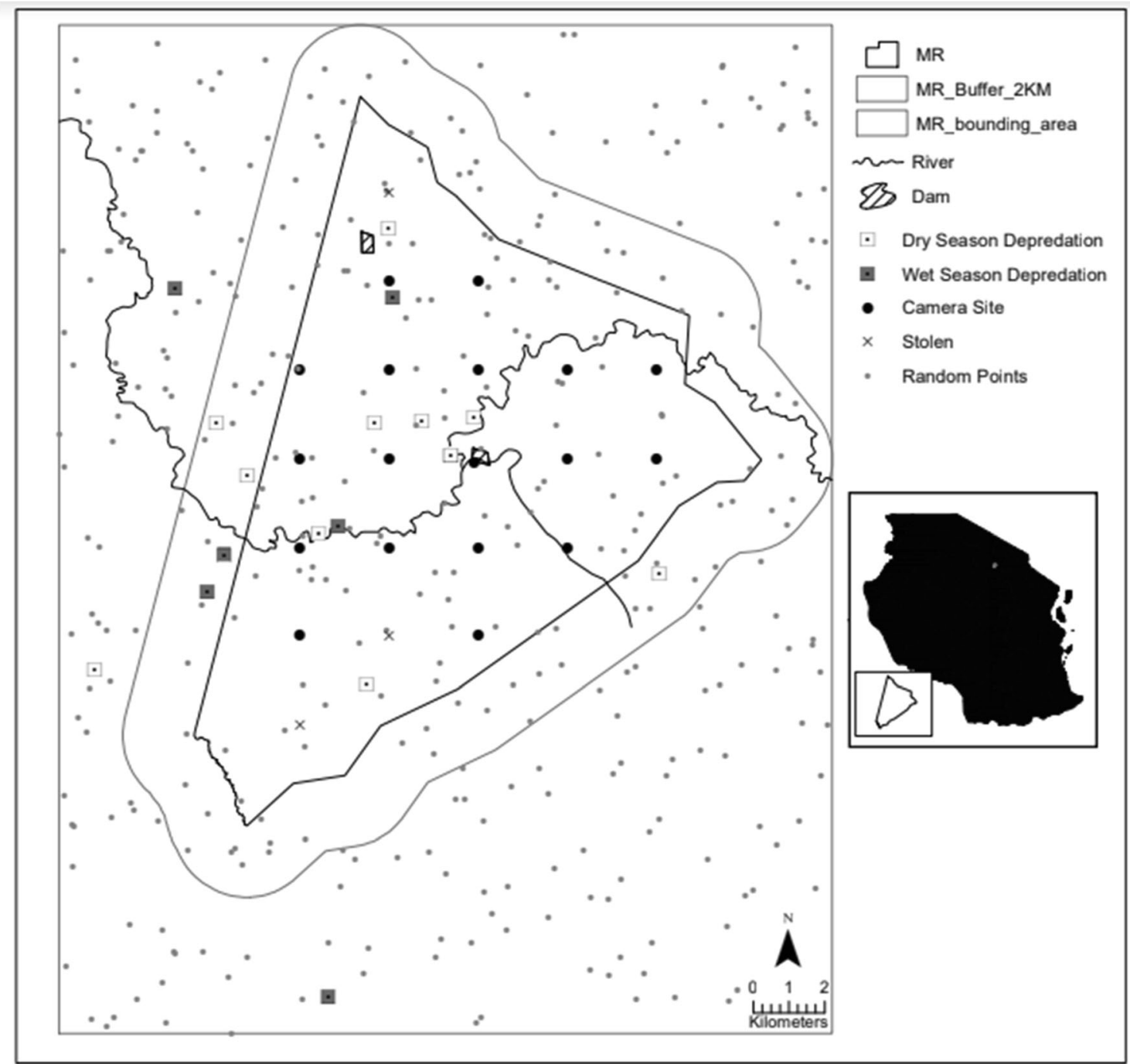

Fig. 1 Locations of camera traps at Manyara Ranch, Tanzania (September to November 2014), systematically distributed background sites, and livestock depredation sites (2013 to 2015). The inset to the right indicates the location of Manyara Ranch in Tanzania

Fig. 2 Average monthly mean rainfall (solid black line \pm 1 se $=$ gray dashed lines) and overall average monthly rainfall (black dashed line). Rainfall data were recorded at Lake Manyara

National Park Main Office from 1953 to 2014

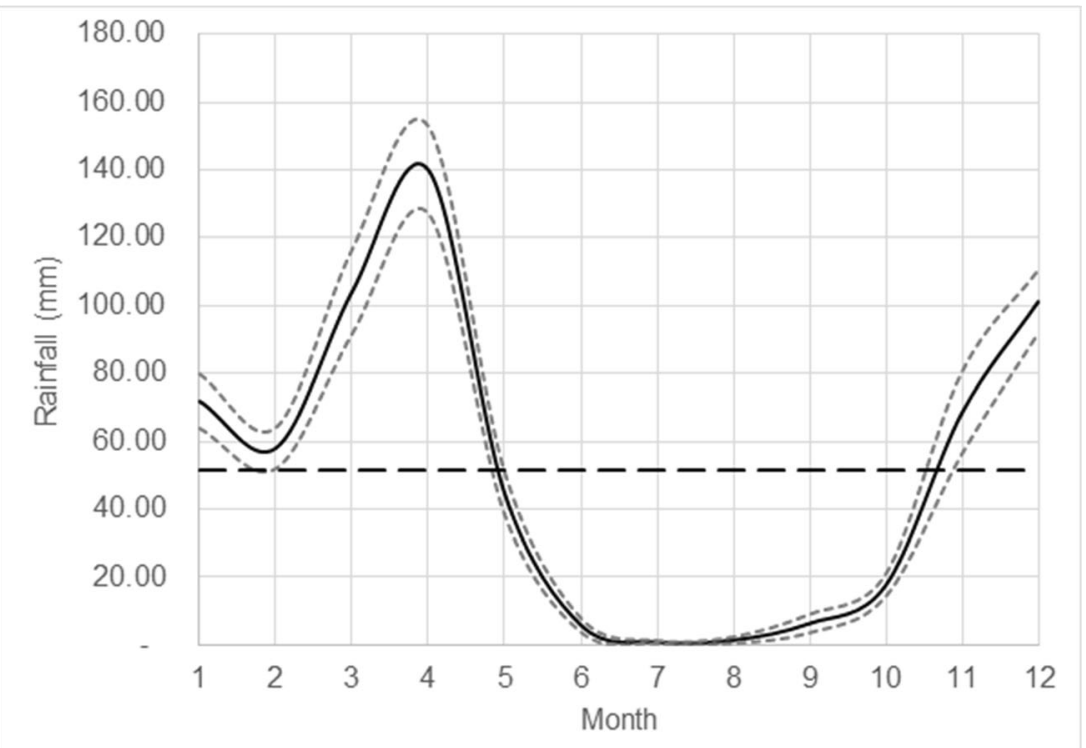


2016). The ranch serves as an important dry season pasture for the surrounding pastoralists and supports a wide array of both resident and migratory wildlife (Kiffner et al. 2016). People living in adjacent communities perceive human-lion conflict as very prevalent (Koziarski et al. 2016).

\section{Survey design}

We used a use-availability resource selection approach to identify risk factors associated with livestock attack sites (Manly et al. 2002). The exact location of attack sites (i.e., affected) were recorded from 2011 to 2015 by the Tarangire Lion Project using a handheld GPS. Eighteen livestock depredation sites were recorded on MR during 2011 to 2016. We used all available data for our survey period; however, we acknowledge some events could have gone undetected. We classified each depredation site as either occurring in the wet or dry season defined as months with higher or lower than average 1953-2016 rainfall, respectively (Fig. 2). Rainfall data were obtained from Lake Manyara National Park headquarters (approx. $20 \mathrm{~km}$ from Manyara Ranch and at same altitude) from 1953 to 2016 (Fig. 2).

Relative abundance of livestock and wildlife was assessed using camera traps (ten Bushnell Trophy Cam HD and four Reconyx PC800 Hyperfire IR) placed on a $2.5-\mathrm{km}$ systematic grid $(n=18)$ as well as on known livestock depredation sites during 2014 ( $n=6$; some locations had multiple depredation events). Camera traps were rotated randomly at background sites every 2 weeks to a new location. Camera traps placed at livestock depredation sites remained stationary for the entire study period, but were maintained every 2 weeks. We installed camera traps to coincide with the end of the dry season (September to November 2014).

We set each camera to take a series of three consecutive images following a trigger event, with a 1-s delay between trigger events and classified an image series as an event using criteria similar to O'Brien et al. (2003). Each event was categorized by the species present during the event. We estimated the number of individuals present during each event. Prey species were divided into wild and domestic prey. Wild prey for lions was classified following Hayward and Kerley (2006) (Online Resource 1). All domestic animals (cattle Bos taurus, sheep Ovis aries, goats Capra aegagrus hircus, donkeys Equus africanus) were considered domestic prey. In order to understand whether relative livestock and prey densities were related to livestock depredation risk, we modeled and predicted the relative abundance of livestock (defined as livestock events/trap night) and wildlife (defined as wildlife events/trap night) using the inverse distance weighted tool in ArcMap 10.3 on the map.

\section{Geospatial and remote sensing data}

We assessed relative vegetative productivity, proximity to surface water, and proximity to livestock enclosures (i.e., bomas) using geospatial techniques. For proximity to surface water, we used ArcMap 10.3 to modify existing, but incomplete geospatial data to include all surface water resources in Manyara Ranch that were present year-round. We then determined proximity to surface water by calculating the nearest distance between affected and unaffected locations and surface water. To examine how seasonal livestock practices influenced risk of depredation, we calculated the distance from kill sites to unaffected sites and to bomas.

To estimate relative vegetative productivity, we acquired three relatively cloud-free (November, 1999, September, 2000, and November, 2009) Landsat 7 satellite images for path 168 row 63 from USGS Earth Explorer with standard terrain correction (Level 1T; no SLC-off). We compensated for sensor and atmospheric influences by applying a radiometric correction in ENVI 5.1; using the dark object subtraction method (Chavez 1996). Next, we converted the digital numbers to reflectance using the Landsat 7 reflectance conversion tool in ERDAS Imagine 2015 (ERDAS Inc 2015). Model parameters such as solar elevation, solar distance, and bias and gain for each band were entered for each image band. This resulted in a reflectance image used to calculate the Normalized Difference Vegetation Index (Eq. 1) for each image.

$\mathrm{NDVI}=\frac{\text { near infrared-visible red }}{\text { near infrared }+ \text { visible red }}$

We averaged NDVI values for the three images in ArcMap 10.3 using the Raster Calculator tool to account for interannual variation in productivity. Effectively, this averaged NDVI data represented relative vegetative productivity during the dry season for our study site (i.e., vegetation productivity at its lowest point during the year). We used averaged NDVI data to calculate the mean NDVI value within a $2.5 \mathrm{~km}$ radius of each affected and unaffected site using the Focal Statistics tool in ArcMap 10.3.

\section{Statistical analysis}

We tested all variables for collinearity and using $r= \pm 0.7$ as a threshold (Dormann et al. 2013) we found no collinearity between variables. We used logistic regression and second order Akaike Information Criterion $\left(\mathrm{AIC}_{\mathrm{c}}\right.$ ) to identify predictive models of lion depredation risk. The binary response variable was the presence of livestock depredation, where one represents a recorded kill site, and zero represents a nondepredation (background) site. We fitted four separate models. We first tested the effects of ecological (including prey availability) and geospatial variables on livestock depredation risk 
for Manyara ranch. Next, we developed a non-seasonal model considering only geospatial variables for Manyara ranch for the entire year. Finally, we developed two seasonal models (i.e., wet and dry seasons) considering geospatial variables. We established background data (pseudo-unaffected sites) using the Create Random Point tool in ArcMap 10.3 and created 360 pseudo-unaffected (Fig. 1: ESRI, Redlands, California, USA) (Fig. 1). For model selection, we used AICc to rank a priori models relative to the null model. We then model averaged the coefficients from all models to evaluate the importance of each factor.

Statistical analysis was performed using the standard $\mathrm{glm}$ function and the MuMIn package (Barton 2015) in R 3.1.3 (R Development Core Team 2013). We primarily assessed models based on model sensitivity (i.e., model correctly classifies affected sites) versus specificity (i.e., model correctly classifies unaffected sites). We focused on model sensitivity because we would expect our model to classify some unaffected areas as affected as we allowed our pseudo-unaffected sites to commingle with our affected sites (i.e., it is likely that some of our pseudo-unaffected sites would, in reality, be risky).

\section{Risk map}

To support conservation efforts, we produced a visual representation using the best model for livestock depredation risk year-round, and separately for dry and wet seasons. We created a risk map of livestock depredation within Manyara Ranch, a 2-km buffer around the ranch, and a buffer containing all reported livestock depredation points using the most highlyranked spatial variables (Olson et al. 2014; Olson et al. 2019). We generated the risk map using the Raster Calculator tool at the resolution of $30 \mathrm{~m}$ (Landsat pixel resolution). We used a threshold of $\mathrm{P}($ Affected $) \geq 0.05$, $\geq 0.02$, and $\geq 0.03$ to differentiate between affected and unaffected sites, which corresponds to the probability of randomly selecting an affected site for three different time periods: year-round, dry season, and wet season, respectively $(0.05=18 \mathrm{affected} / 378$ total; $0.02=12$ affected $/ 372$ total; $0.03=6 \mathrm{affected} / 366$ total). Prevalence of affected sites is typically the most optimal predictive threshold (Stokland et al. 2011; Olson et al. 2012; Olson et al. 2014).

Risk maps can be only marginally valuable for livestock and wildlife coexistence if they fail to examine more than cooccurrence of predators and domestic animals (Olson et al. 2019). Therefore, we tested for the relationship between risk and NDVI in order to identify potential alternative grazing areas of low risk. We first used a linear regression to test for a relationship between risk and NDVI to ensure the relationship was non-linear. We then constructed a risk map overlaying NDVI to identify contiguous areas of low risk that also had relatively high NDVI values (i.e., hypothetically low risk grazing areas). This a posteriori analysis was critical in terms of assessing the practicality of our recommendations, an assessment that is often overlooked when presenting risk maps (Olson et al. 2019).

\section{Results}

We collected over 570 trap nights (TN) worth of camera trap data from September to November 2014 on Manyara Ranch Conservancy, including 86,682 images. A total of 1639 camera trap events were recorded, and 34 wild mammal species and 3 large avian species were observed and identified (Online Resource 1 and 2). We documented 14 wild prey species on Manyara Ranch (Online Resource 1). Wild prey (0.944 events/TN) had a higher relative abundance compared to livestock (cattle, sheep, goats, donkeys: 0.646 events/TN). However, livestock had the highest number of individuals observed over all trap nights combined (overall: 24.35 individuals/TN; cattle: 18.6 individuals/TN; sheep and goats: 5.6 individuals/TN; donkeys: 0.23 individuals/TN), and they were observed at 23 of the 24 sites across Manyara Ranch. Our camera traps captured three wild carnivore species; blackbacked jackal (Canis mesomelas), spotted hyena (Crocuta crocuta), and lions. Two events documented a total of six lions on the Ranch at two prior livestock depredation sites (sites 3 and 11; Fig. 1).

Eighteen livestock depredation sites were recorded between 2011 and 2016 inside and in the surrounding local communities of Manyara Ranch Conservancy (Fig. 1). Twelve events occurred in the dry season and 6 occurred in the wet season. The mean NDVI of the livestock depredation sites ranged from 0.166 to 0.249 whereas the pseudounaffected sites ranged from 0.050 to 0.263 ( 0 represents low vegetation productivity and 1 represents high vegetation productivity). Distance between livestock depredation sites to nearest surface water ranged from 14 to $8928 \mathrm{~m}$ and distance from depredation sites to nearest boma ranged from 17 to $5692 \mathrm{~m}$. Background sites were located between 21 to $14,015 \mathrm{~m}$ from surface water and between 6 to $7507 \mathrm{~m}$ to the nearest bomas.

\section{Non-seasonal ecological and geospatial livestock depredation risk}

Mean NDVI and wild prey were present in the top two models, and mean NDVI being in the top five models. Mean NDVI had an importance value of 0.79 and wild prey 0.53 (Table 1). Mean NDVI and wild prey abundance were both significantly and positively associated with risk of lion depredation (Online Resource 3). Lion depredation risk was positively associated with vegetative productivity and negatively associated with wild prey density and distance to surface water. 
Table 1 Model averaged logistic regression coefficients, standard errors (adjusted), $p$ values $(p)$, and importance values for estimating the likelihood of livestock depredation risk year-round by African lions in Manyara Ranch, Tanzania using ecological and geospatial variables

\begin{tabular}{lllll}
\hline Factors & Estimate & Standard error & $p$ & Importance \\
\hline Intercept & 0 & 0 & NA & NA \\
Mean NDVI & 1.42 & 4.51 & 0.75 & 0.79 \\
Wild Prey & -33.99 & 76.23 & 0.66 & 0.53 \\
Mean NDVI * Wild Prey & 35.82 & 78.06 & 0.65 & 0.26 \\
Dist. Water & -3.737 & 20.02 & 0.85 & 0.29 \\
Livestock & 1.13 & 12.8 & 0.93 & 0.14 \\
Mean NDVI* Dist. Water & 2.51 & 17.36 & 0.89 & 0.04 \\
Wild Prey * Dist. Water & -0.15 & 1.21 & 0.9 & 0.03 \\
Livestock * Mean NDVI & -0.95 & 12.68 & 0.94 & 0.02 \\
Livestock * Dist. Water & -0.01 & 0.32 & 0.97 & 0.01 \\
Livestock * Wild Prey & -0.01 & 0.23 & 0.97 & $<0.01$ \\
\hline
\end{tabular}

\section{Non-seasonal geospatial livestock depredation risk}

Mean NDVI and proximity to surface water were present in the top five models with a weight greater than 0.15 suggesting that these are likely important factors in determining high risk areas on Manyara Ranch (Table 2 and Online Resource 4). Of all factors tested, distance to surface water (1.00), mean NDVI (0.89), and distance to boma (0.62) showed the highest importance values in determining livestock depredation sites on Manyara Ranch (Table 2).

Overall, the best fit model included the variables mean NDVI, distance to surface water, and the interaction between them with a weight of 0.20 (Online Resource 4). Our model produced a $72 \%$ sensitivity (13 of 18 sites identified correctly) and $71 \%$ specificity ( 255 of 360 unaffected sites identified correctly).
Using the model with highly ranked spatial variables, mean NDVI, and proximity to surface water (Table 2 and Online Resource 4), we created a human-lion conflict risk map for Manyara Ranch and the encompassing area including all depredation sites (Fig. 3) using Eq. 2:

$P($ Affected $)=1 /\left(1+e^{-(-9.60+0.001 \text { DistWater }+39.22 N D V I-0.01 N D V I * D i s t \text { Water })}\right)$

\section{Dry season geospatial livestock depredation risk}

Mean NDVI and distance to surface water were present in the top four models with a weight greater than 0.09 suggesting that vegetative productivity and distance to
Table 2 Second-order Akaike information criterion scores $\left(\mathrm{AIC}_{\mathrm{c}}\right), \Delta \mathrm{AIC}_{\mathrm{c}}$, and model weights of logistic regression models predicting livestock depredation risk year-round by African lions, using ecological and geospatial variables

\begin{tabular}{llll}
\hline Model & $\mathrm{AIC}_{\mathrm{c}}$ & $\Delta \mathrm{AIC}_{\mathrm{c}}$ & Weight \\
\hline Mean NDVI + Wild Prey + Mean NDVI*Wild Prey & 23.03 & 0 & 0.26 \\
Mean NDVI + Wild Prey & 23.87 & 0.84 & 0.17 \\
Mean NDVI & 24.39 & 1.37 & 0.13 \\
Mean NDVI + Dist. Water & 25.17 & 2.14 & 0.09 \\
Mean NDVI + Livestock & 25.54 & 2.51 & 0.07 \\
Dist. Water & 25.78 & 2.75 & 0.07 \\
Mean NDVI + Dist. Water + Mean NDVI*Dist. Water & 26.6 & 3.57 & 0.04 \\
Wild Prey + Dist. Water & 26.62 & 3.59 & 0.04 \\
Wild Prey + Dist. Water + Wild Prey * Dist. Water & 27.53 & 4.5 & 0.03 \\
Livestock + Mean NDVI + Livestock*Mean NDVI & 27.99 & 4.96 & 0.02 \\
Livestock + Dist. Water & 28.35 & 5.33 & 0.02 \\
Wild Prey & 29.05 & 6.03 & 0.01 \\
Null & 29.17 & 6.15 & 0.01 \\
Livestock + Wild Prey & 29.28 & 6.25 & 0.01 \\
Livestock & 30.25 & 7.22 & 0.01 \\
Livestock + Dist. Water + Livestock*Dist. Water & 30.85 & 7.83 & 0.01 \\
Livestock + Wild Prey + Livestock* Wild Prey & 31.27 & 8.24 & 0 \\
\hline
\end{tabular}




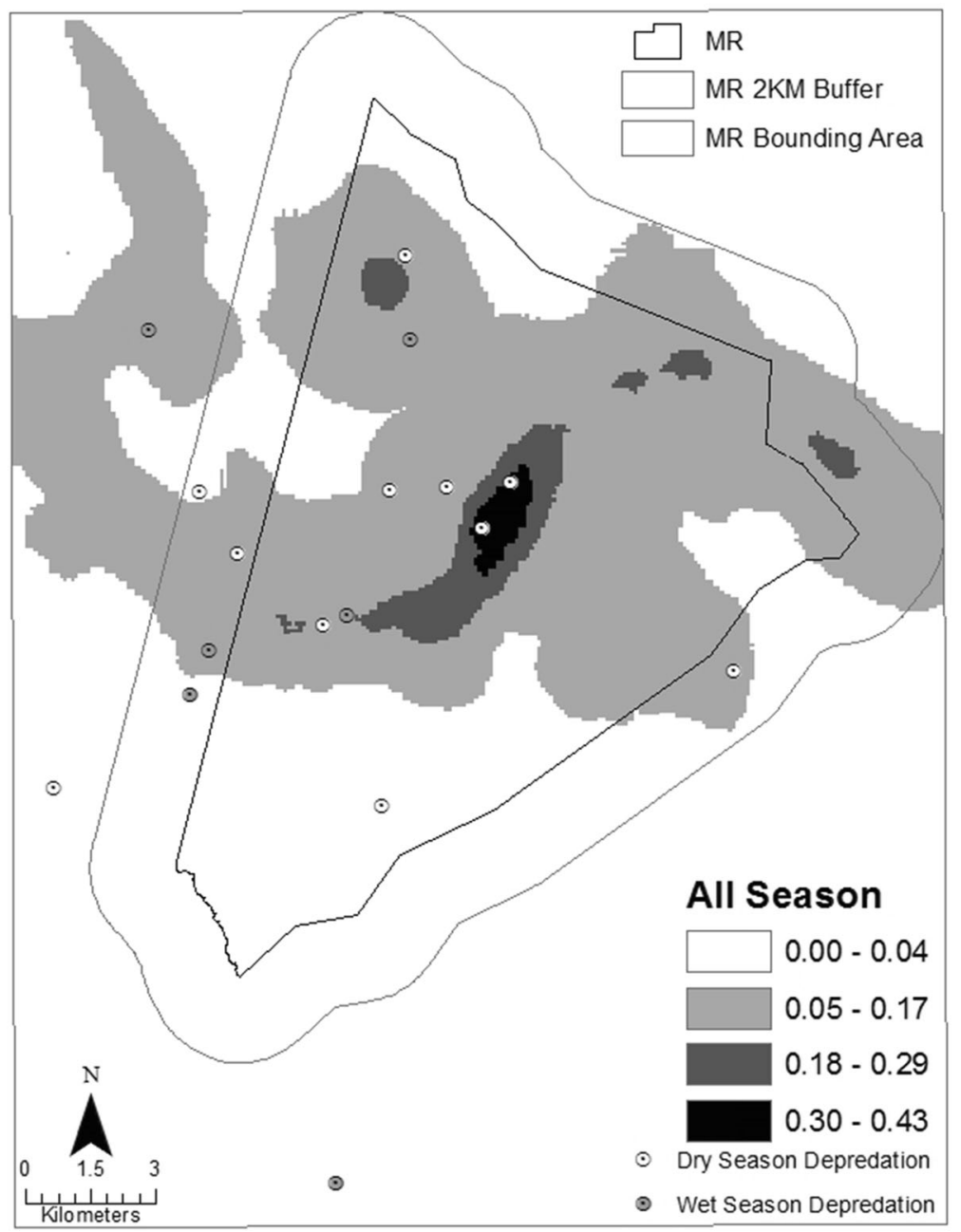

a

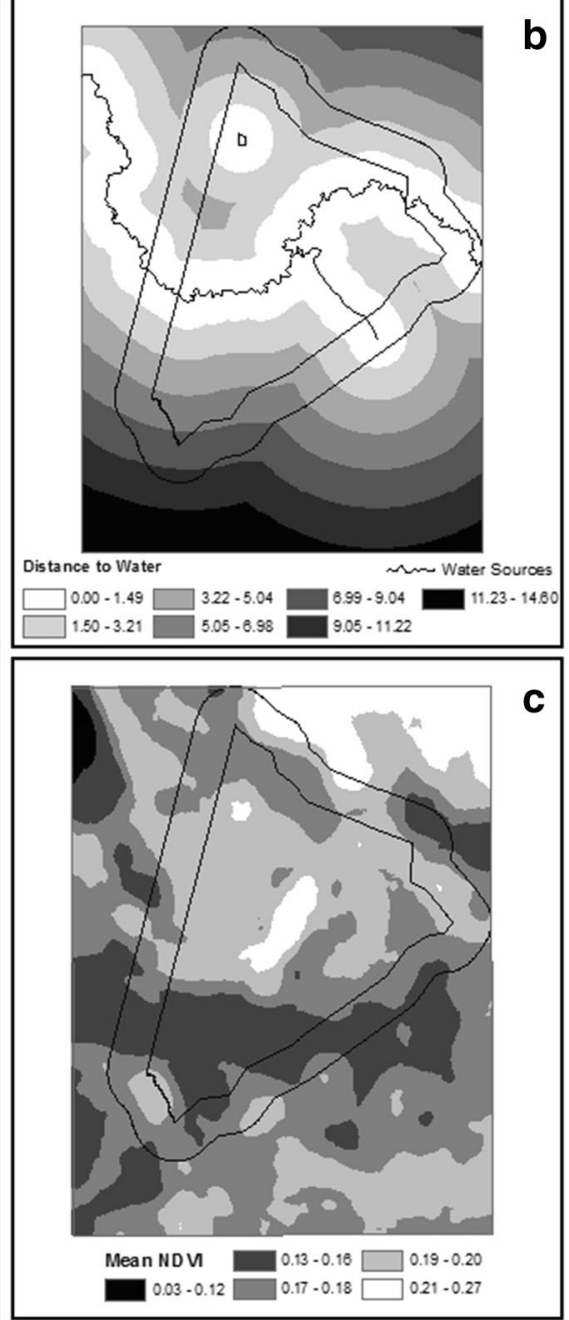

Fig. 3 a Predicted livestock depredation risk in Manyara Ranch across wet and dry seasons, using $\mathbf{b}$ distance to water (km) and $\mathbf{c}$ mean NDVI as explanatory variables. For a: $0.00-0.04=$ unaffected; $0.05-0.17=$ low risk; $0.18-0.29=$ medium risk; $0.30-0.43=$ high risk

surface water are likely important factors in determining high risk areas on Manyara Ranch during the dry season (Table 3 and Online Resource 4). Of all factors tested, distance to water (1.00), mean NDVI (0.93), and distance to water interacting with mean NDVI (0.68) showed the highest importance values in determining livestock depredation sites on Manyara Ranch (Table 3).

Overall, the best fit model described livestock depredation risk as a function of mean NDVI, distance to surface water, and the interaction between them with a weight of 0.48 (Table 3). Our model produced a $75 \%$ sensitivity $(9$ of 12 sites identified correctly) and $70.5 \%$ specificity ( 254 of 360 unaffected sites identified correctly).

Using the model with highly ranked spatial variables, mean NDVI, and proximity to surface water (Table 3 and Online Resource 4), we created a human-lion conflict risk map for Manyara Ranch and the encompassing area including all depredation sites for the dry season (Fig. 4) using Eq. 3:

$P($ Affected $)=1 /\left(1+e^{-(-10.79+0.002 \text { DistWater }+44.13 N D V I-0.01 N D V I * \text { DistWater })}\right)$

\section{Wet season geospatial livestock depredation risk}

Distance to boma and distance to surface water were present in the top four models with a weight greater than 0.09 suggesting that these are likely important factors in determining high risk areas on Manyara Ranch during the wet (Table 3 and Online Resource 4). Of all factors tested, distance to surface water (0.75), mean NDVI (0.43), and 
Table 3 Model averaged logistic regression coefficients, standard error (adjusted), $p$ value ( $p$ ), and importance for estimating the likelihood of livestock depredation by lions year-round (all year), during the dry season (dry), and during the wet season (wet) for Manyara Ranch, Tanzania

\begin{tabular}{|c|c|c|c|c|c|c|c|c|c|c|c|c|}
\hline \multirow[b]{2}{*}{ Factors } & \multicolumn{4}{|l|}{ All year } & \multicolumn{4}{|l|}{ Dry } & \multicolumn{4}{|l|}{ Wet } \\
\hline & Estimate & $\begin{array}{l}\text { Standard } \\
\text { error }\end{array}$ & $p$ & Importance & Estimate & $\begin{array}{l}\text { Standard } \\
\text { error }\end{array}$ & $p$ & Importance & Estimate & $\begin{array}{l}\text { Standard } \\
\text { error }\end{array}$ & $p$ & Importance \\
\hline Intercept & 0.00 & 0.00 & NA & NA & 0.00 & 0.00 & NA & NA & 0.00 & 0.00 & NA & NA \\
\hline Dist. Water & 5.86 & 16.36 & 0.72 & 1.00 & 27.23 & 29.85 & 0.36 & 1.00 & -2.52 & 12.90 & 0.85 & 0.75 \\
\hline Mean NDVI & 2.92 & 2.43 & 0.23 & 0.89 & 4.39 & 3.19 & 0.17 & 0.93 & 2.20 & 4.28 & 0.61 & 0.43 \\
\hline $\begin{array}{l}\text { Mean NDVI * Dist. } \\
\text { Water }\end{array}$ & -10.92 & 16.75 & 0.51 & 0.39 & -36.86 & 31.61 & 0.24 & 0.68 & 0.18 & 10.88 & 0.99 & 0.05 \\
\hline Dist. Boma & -3.51 & 8.72 & 0.69 & 0.62 & -2.79 & 9.31 & 0.77 & 0.36 & -2.00 & 13.19 & 0.88 & 0.72 \\
\hline $\begin{array}{l}\text { Dist. Boma * Dist. } \\
\text { Water }\end{array}$ & -3.06 & 6.68 & 0.65 & 0.25 & -0.40 & 2.81 & 0.89 & 0.04 & -27.36 & 42.61 & 0.52 & 0.43 \\
\hline $\begin{array}{l}\text { Dist. Boma * Mean } \\
\text { NDVI }\end{array}$ & 3.16 & 8.37 & 0.71 & 0.17 & 2.70 & 9.49 & 0.78 & 0.10 & 0.16 & 12.34 & 0.99 & 0.06 \\
\hline
\end{tabular}

distance to boma (0.72) showed the highest importance values in determining livestock depredation sites on Manyara Ranch (Table 3).

Overall, the best fit model included the variables distance to boma, distance to surface water, and the interaction between them with a weight of 0.25 (Online Resource 4 ). Our model produced an $83 \%$ sensitivity (5 of 6 sites identified correctly) and $63 \%$ specificity (226 of 360 unaffected sites identified correctly).

Using the highly ranked spatial variables, distance to boma, distance to surface water, and their interaction (Table 3 and Online Resource 4), we created a livestock depredation risk map for Manyara Ranch and the encompassing area including all depredation sites for the wet season (Fig. 4) using Eq. 4:

$P($ Affected $)=1 /\left(1+e^{-\left(-2.86+1.86 e^{-05} \text { DistWater }+1.21 e^{-04} \text { DistBoma-7.14DistWater*DistBoma }\right)}\right)$

\section{Evaluation of livestock depredation risk}

Livestock depredation risk was significantly correlated with NDVI (positive association), wild prey abundance (positive association), and distance from surface water (negative association; Fig. 5). Both livestock and wildlife abundance were highest in areas with high risk, though livestock also utilized areas with minimal risk (Fig. 6). Lion observations on the ranch occurred in areas of both high and low risk (Fig. 6). The areas of the highest NDVI were found in relatively high-risk areas, though there were non-risky areas that did have high NDVI values (Fig. 7).

\section{Discussion}

The survival of lions in Africa depends, in part, on the ability of conservation entities, government agencies, and communities to prevent, mitigate, and address human-lion conflict. Identifying areas of high risk for livestock depredation can greatly help conservationists and pastoralists better understand and minimize risk of conflict. Our models suggest that livestock depredation by lions differs seasonally and largely follows the 'prey catchability' hypothesis across the landscape (i.e., lions attack livestock in sites near to surface water and in areas of high vegetation productivity) — a pattern that has been established in independent studies on lion hunting success in fully protected areas as well (e.g., Hopcraft et al. 2005). Despite the apparent importance of 'prey catchability' in predicting livestock depredations on Manyara Ranch, wild prey abundance (i.e., 'prey availability') was also an important predictor for lion attack risk on livestock.

On a broad scale, it is known that the density of prey species has an impact on the spatial distribution and density of lions (East 1984; Ritchie and Olff 1999; Carbone and Gittleman 2002). Similar to the Valeix et al.'s (2012) study which found that abundance of wild prey and livestock species were crucial predictors of lion attacks on livestock, our results indicate that the abundance of lions' preferred wild prey was important in determining areas of high risk for livestock depredation by lions but livestock abundance was not. Our results showed that high vegetation productivity and wild prey abundance were important in determining areas of high risk for livestock depredation. Tentatively, these results suggest that lions prefer to hunt in areas with high wild prey density and then opportunistically prey on livestock.

During the dry season, medium-sized herbivores frequently concentrate in areas close to surface water, which often tend to have relatively higher vegetative productivity (Bhola et al. 


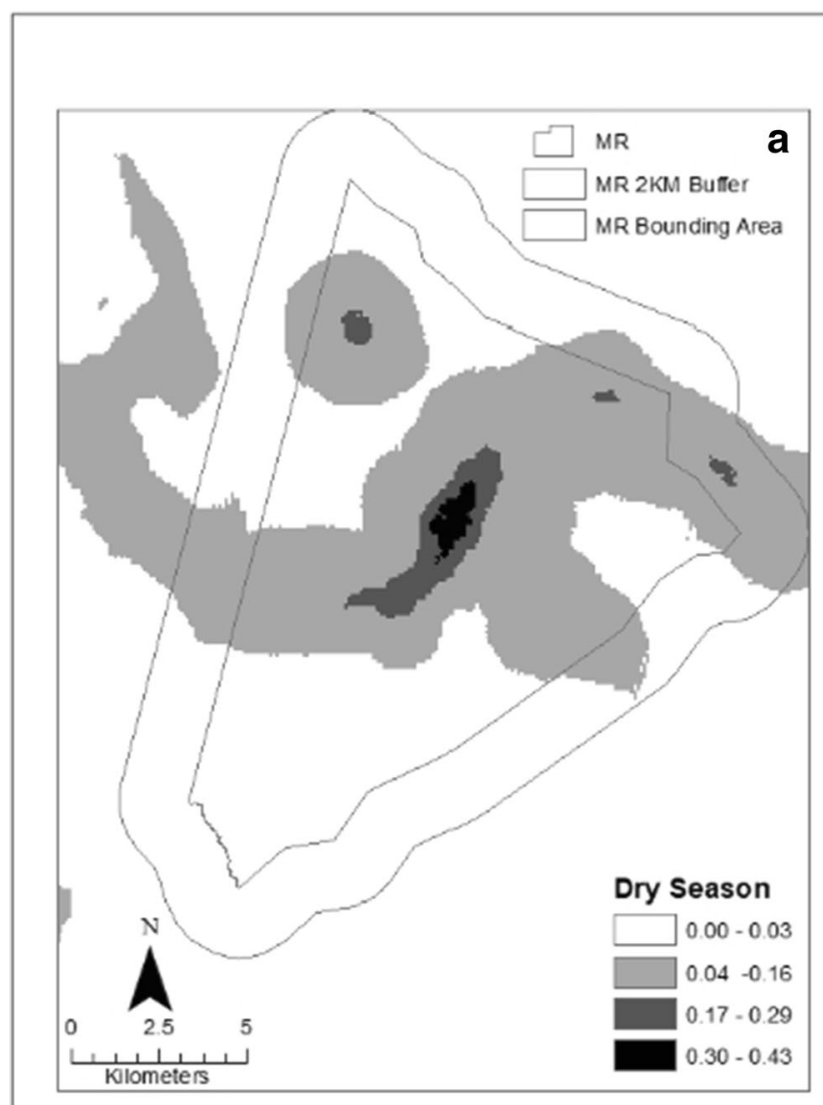

Fig. 4 Predicted livestock depredation risk by lions during a dry season and $\mathbf{b}$ wet season in Manyara Ranch, Tanzania. The dry season risk map is predicted using distance to water $(\mathrm{km})$ and mean NDVI: $0.00-0.03=$ unaffected; $0.04-0.16=$ low risk; $0.17-0.29=$ medium risk; $0.30-0.43$

2012). In the dry season, the limited amount of food and water resources lead to a concentration of livestock grazing in areas close to water or wetlands, and, coincidentally, near wildlife

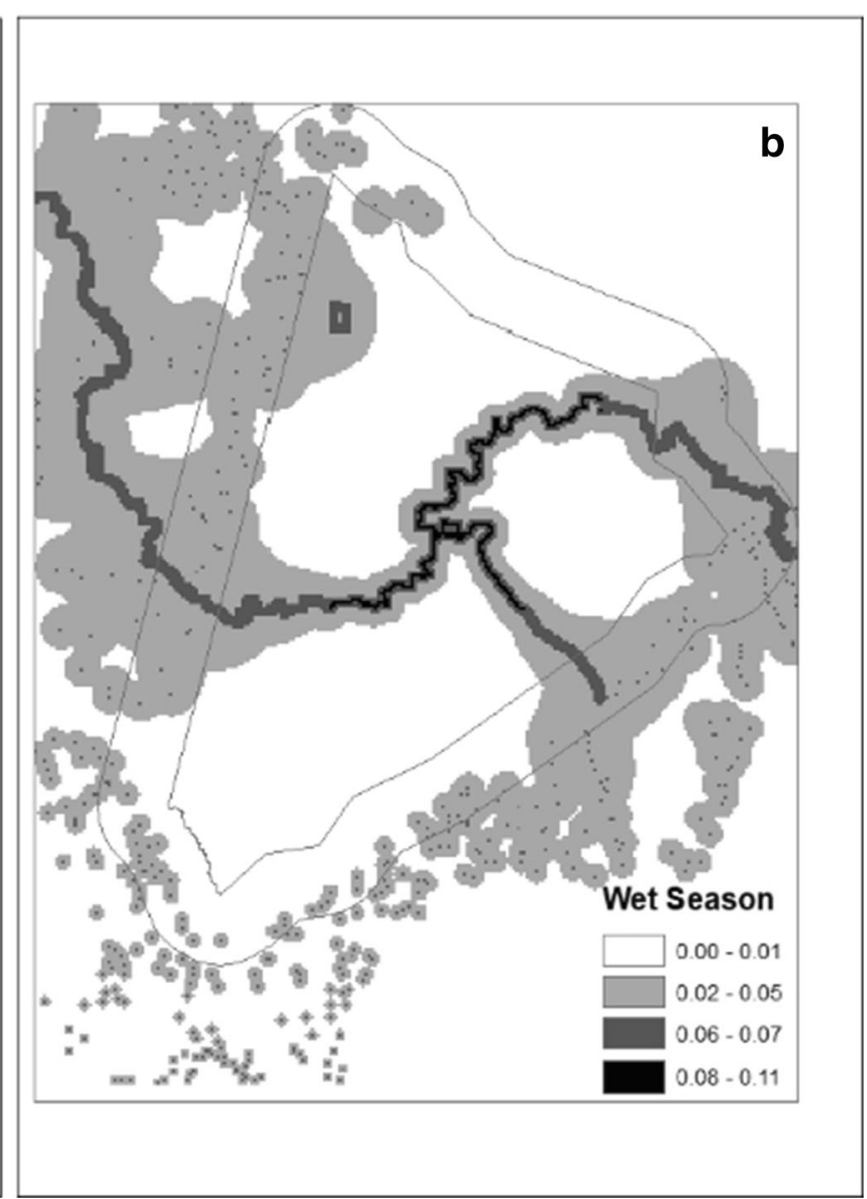

$=$ high risk. The wet season risk map is predicted based on distance to water $(\mathrm{km})$ and distance to boma: $0.00-0.01=$ unaffected; $0.02-0.05=$ low risk; $0.06-0.07=$ medium risk; $0.08-0.11=$ high risk

(Okello 2005). Our results indicate that the likelihood of livestock depredation by lions was highest near water and in areas with high vegetative productivity, similar to other studies
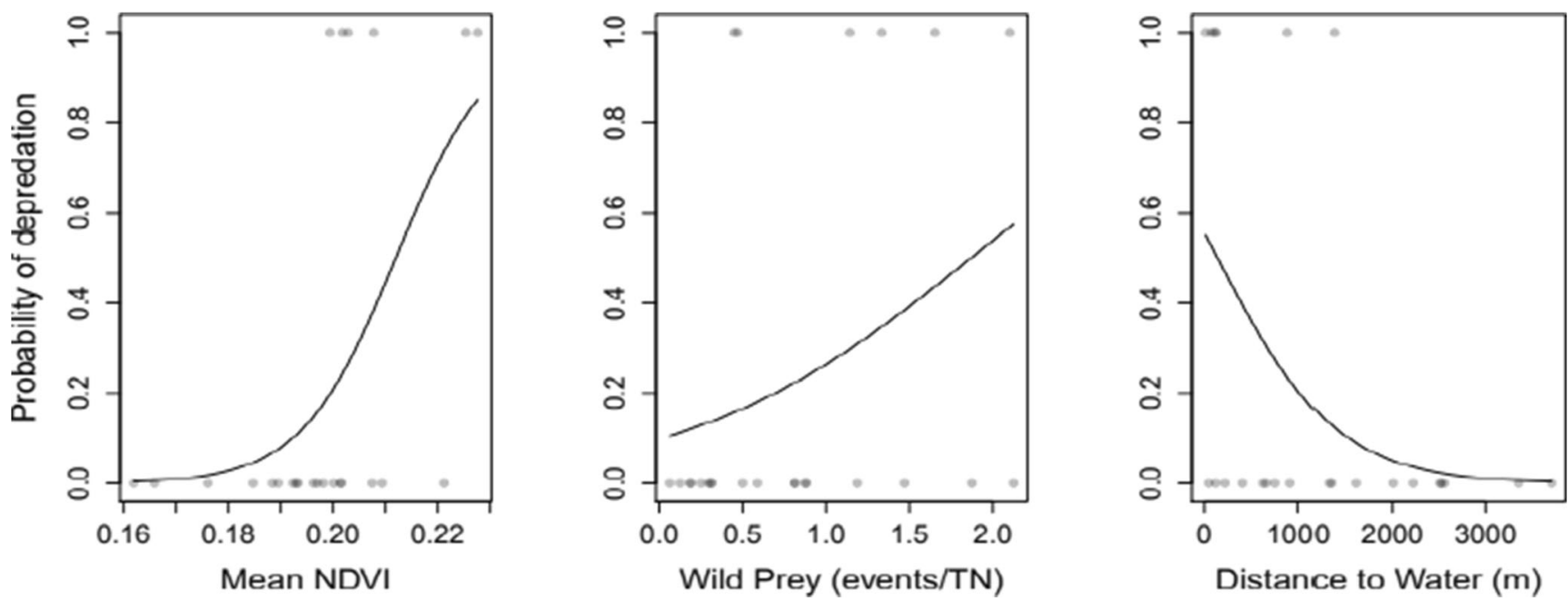

Fig. 5 Probability of livestock depredation by African lions in relation to (left panel) mean normalized difference vegetation index (NDVI), (middle panel) relative wild prey abundance, and (right panel) distance to water 

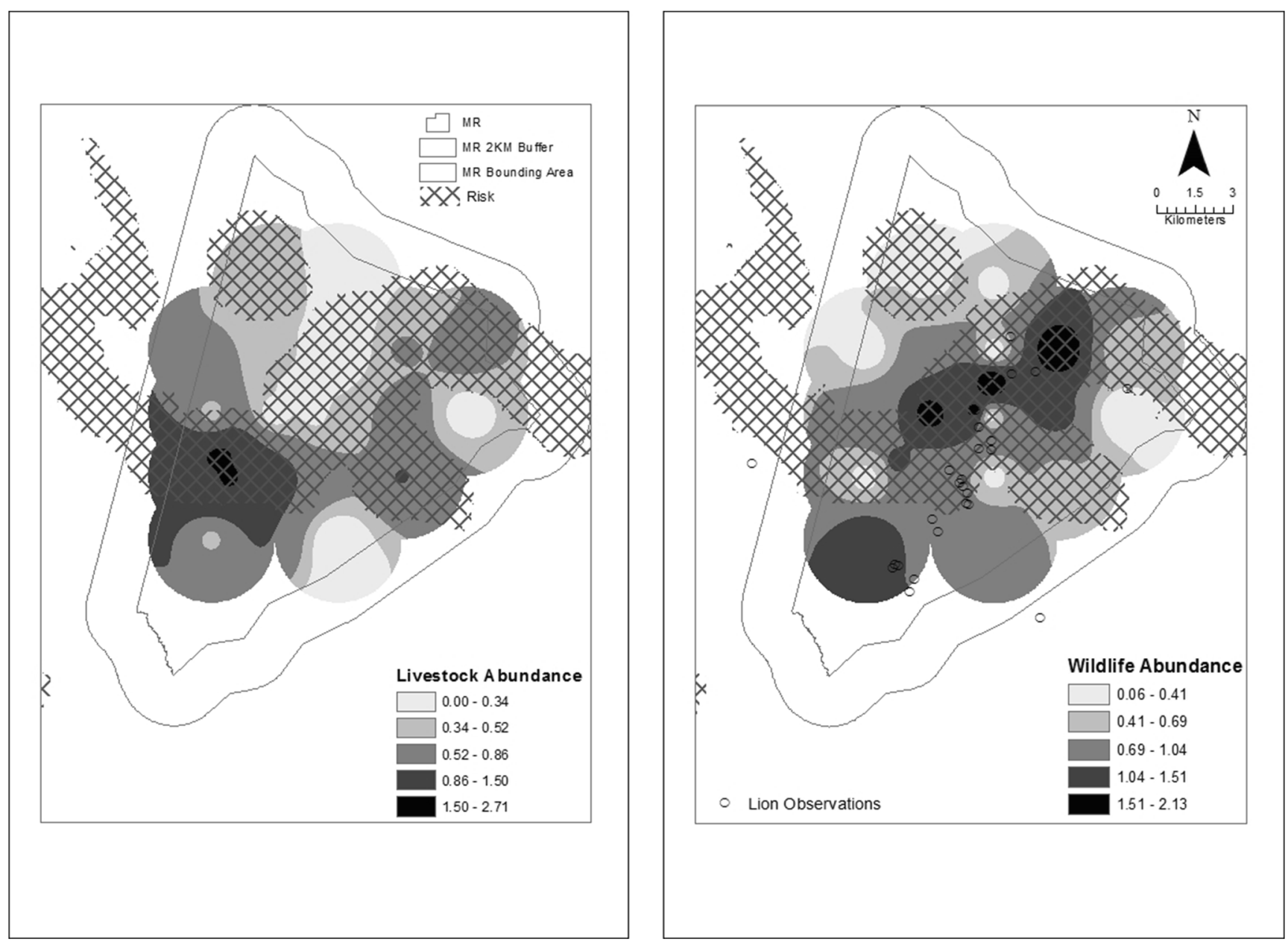

Fig. 6 Predicted livestock depredation risk by lions during the dry season overlaid with a relative livestock abundance and $\mathbf{b}$ relative wildlife abundance based on camera trap data and observation data of lions (Panthera leo)

which found that during the dry season, lions prey upon livestock closer to surface water (Butler 2000; Kays and Patterson 2002; Hopcraft et al. 2005; Michalski et al. 2006; Boer et al. 2010). The presence of surface water is frequently associated with relatively abundant vegetative cover, another important landscape feature for ambush-predators like lions (Hopcraft et al. 2005). Lions are opportunistic, stalk-and-ambush hunters that prefer hunting grounds with good vegetative coverage (Schaller 1972; Elliott et al. 1977; van Orsdol 1984; Packer et al. 1990; Scheel and Packer 1991; Stander 1992; Scheel 1993; Stander and Albon 1993; Packer and Pusey 1997). Our model including all depredation points indicates that areas near water resources predict high risk for livestock depredation. Thus, surface water and the associated vegetative cover are likely high-risk areas for both wild and domestic prey during the dry season.

Surface water and vegetative productivity usually become more widespread during the rainy season (Laizer et al. 2014). As water is more freely available, wild prey are more widely distributed across the landscape, which could make it more challenging for lions to find wild prey (Patterson et al. 2004). For the wet season, our model predicts that distance to bomas and surface water are the two most important factors in predicting high risk areas for livestock depredation. Indeed, lions in our study area tend to increase their home range during the wet season (Laizer et al. 2014) and since Manyara Ranch is surrounded by pastoral communities, their likelihood of encountering livestock in village lands likely leads to more frequent opportunistic killing of livestock. Similar to seasonal changes in the distribution of wild prey, seasonal variation in water resources and availability of vegetation leads to seasonal differences in pastoralist animal husbandry practices. As water resources and forage become scarce, pastoralists may graze their livestock closer to water resources with high vegetative productivity further away from their bomas. During the rainy season, water resources and forage become more readily available, and pastoralist can graze closer to their bomas and on village lands as opposed to grazing areas within Manyara Ranch. Seasonal changes in husbandry practices are further mediated by the ranch management which discourages 
Fig. 7 Predicted livestock depredation risk by lions and mean NDVI values of Manyara ranch, Tanzania

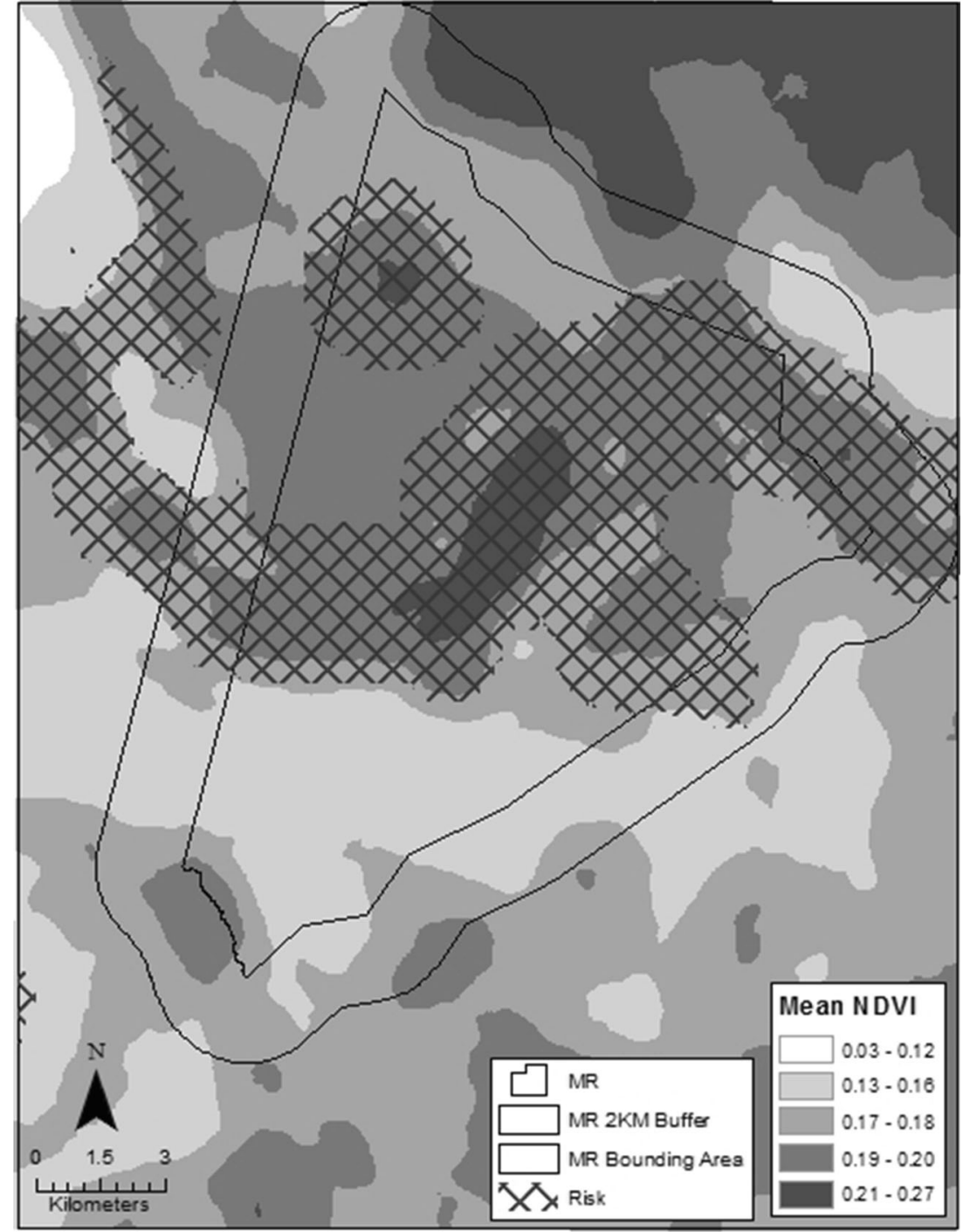

community livestock grazing during the rainy season (but these grazing restrictions are not always adhered to by adjacent pastoralists). This seasonal variation in husbandry practices and grazing access regulations can largely explain the differences between our seasonal models.

In terms of livestock depredation, the dry season was twice as risky as the wet season. Areas of high risk during the dry season appeared to be associated with suitable grazing areas and areas where livestock can drink water. However, during the wet season, livestock depredation risk appeared to be concentrated in proximity to human settlements. Indeed, local people perceive conflicts with lions most strongly during the wet season (Koziarski et al. 2016).

Grazing on Manyara Ranch by outside villages is not permitted on the ranch during the wet season, therefore cattle abundances decrease during the long rains and increase during the dry period (Kiffner et al. 2016) as the ranch is an important drought reserve (Davis and Goldman 2019). Areas of high livestock depredation risk on Manyara Ranch occurred where livestock abundance is at its highest during the dry season (Fig. 6). Livestock abundance during the dry season is highest in areas of high risk, but livestock also use areas of no risk, which are areas of high vegetative productivity. Areas where livestock abundance is low predominantly coincide with areas where vegetative productivity is low. Clearly, avoiding areas of low vegetative productivity (and low depredation risk) is not a solution for pastoralists since nutritional needs of livestock may not be met, therefore other techniques that balance reducing depredation risk and maximizing grazing should be considered. We suggest that the presence of Manyara ranch livestock year round may not have influenced our results because Manyara ranch livestock is effectively herded by employed adults who are more vigilant and effective in preventing predation by lions and other carnivores throughout the year compared to livestock from the villages that is usually herded by youth (Ikanda and Packer 2008). 
To foster coexistence between livestock and wildlife within multi-use conservation areas, we should explore ways in which our research can minimize human-wildlife conflict. Land-sharing strategies are only successful when they support both human livelihoods and biodiversity conservation. Manyara Ranch Conservancy is highly utilized by the surrounding pastoralist communities for its grazing and permanent water sources. We observed a high relative abundance of livestock across our study area. Despite the relatively high abundance of livestock, we also observed relatively high large mammal diversity throughout our study area and multiple threatened species. Yet, lions have killed livestock within the ranch and retaliatory killing of lions is a frequent occurrence (Kissui et al. 2019). Our efforts to mitigate these conflicts must extend beyond a statistical description of risk. Here, we have demonstrated that areas close to water resources and with high vegetative productivity are at higher risk for livestock depredation throughout the year, and that there is a seasonal variation in factors that affect risk. This spatial information can be used to minimize risk of livestock depredation via livelihood-compatible regulations and livestock husbandry practices that proactively attempt to minimize risk, such as exercising caution when watering and grazing livestock especially during the dry season. Preventative measures, such as scouting areas adjacent to water resources to determine lion presence prior to herding cattle into that area, may reduce human-lion conflict.

Lion attacks on livestock were greater in areas with higher wild prey abundance and were not impacted significantly by changes in livestock abundance. This suggests that moving livestock to areas with less wild prey could help pastoralists avoid high risk areas. Providing cautionary warnings and education to local pastoralists about areas that are high risk to livestock could help limit livestock depredation and in return decrease the retaliatory killing of lions. Developing alternative livestock watering (e.g., by having mobile water supplies that are only accessible to livestock) practices could reduce the likelihood of overlap between lions, wild prey, and livestock, and may reduce conflicts with lions, especially during the dry season. In addition, grazing intensity could be reduced during the dry season, especially in high depredation risk areas. The majority $(71.5 \%)$ of the ranch is considered to be low risk (Fig. 3). However, such low-risk areas must be suitable for livestock grazing or these recommendations will fail. Our parsimonious assessment indicates that some areas of low risk do have vegetative productivity that may support livestock grazing (Fig. 7). However, these areas are not as extensive and access to water resources during the dry season will remain a critical issue. Thus, we recommend local ranch managers to work collaboratively with local pastoralists to design and implement grazing regulations and other preventative measures such as intensive monitoring of lion activity. Manyara Ranch is surrounded by Maasai communities that have a cultural connection to lions and wish to see lions maintained on the landscape into the future (Goldman et al. 2013). Collaborations between land managers, communities, and researchers with an understanding of the complexity of Maasailion relations could be critical to the success of lion conservation efforts (Goldman et al. 2010, 2013; Davis and Goldman 2019).

Understanding the landscape of risk for conflict is critical in promoting coexistence between humans and carnivores (Miller et al. 2015), and given the urgency of this conflict, conservation planning is often limited by data availability. Risk maps, that draw upon multiple data sources and are generated using robust statistical methods, can help conservationists identify areas at risk of human-carnivore conflict, supporting conflict mitigation and prevention efforts (Miller et al. 2015; Carvalho Jr et al. 2015).

Our risk map allows researchers, conservationists, and pastoralists to visualize areas of high risk; however, it is bound by the assumptions inherent in data collection and model selection and therefore we do not expect this risk map to represent all aspects of risk faced by livestock within Manyara Ranch (see Olson et al. 2019). Rather, we hope this will be a valuable contribution to discussions around the many needs of livestock owners, wild prey, and lions on multiple-use areas of East Africa (Schuette et al. 2013).

Acknowledgments This study was carried out under the following governmental permits: TAWIRI/COSTECH 2013- 316-NA-2013-191, 2014 324-ER-2013-191. We would like to thank the staff, faculty, and students of Northland College and the School for Field Studies for their support. We thank Dr. S. Ventura (UW-Madison), Dr. R. Sears (School for Field Studies), Manyara Ranch Conservancy, Manyara Ranch Rangers for their assistance. We thank the Tarangire Lion Project for providing the historical data on livestock depredation in Manyara ranch, and the Lion Guardians (Tanzania) for their assistance. We thank two anonymous peer reviewers for their comments on an earlier version of this work. We thank the ecology department of Lake Manyara National Park for providing rainfall data. We acknowledge National Aeronautics and Space Administration (NASA) and the US Geological Survey (USGS) for preprocessing and providing access to Landsat 7 satellite imagery. Funding was provided, in part, by Brother Bear and McLean Travel Grants, and the Parsonage Fund at Northland College.

\section{References}

Azevedo FCC (2008) Food habits and livestock depredation of sympatric jaguars and pumas in the Iguaçú National Park area, South Brazil. Biotropica 40:494-500

Barton K (2015) MuMIn: Multi-model inference. R package version 1.13.4. https://CRAN.R-project.org/package=MuMIn

Bauer H, Chapron G, Nowell K, Henschel P, Funston P, Hunter LTB, Macdonald DW, Packer C (2015) Lion (Panthera leo) populations 
are declining rapidly across Africa, except in intensively managed areas. PNAS. https://doi.org/10.1073/pnas.1500664112

Behdarvand N, Kaboli M (2015) Characteristics of gray wolf attacks on humans in an altered landscape in the west of Iran. Hum Dimens Wildl 20(2):112-122

Bencin H, Kioko J, Kiffner C (2016) Local people's perceptions of wildlife species in two distinct landscapes of northern Tanzania. J Nat Conserv 34:82-92

Bhola N, Ogutu JO, Piepho HP, Said MY, Reid RS, Hobbs NT, Olff H (2012) Comparative changes in density and demography of large herbivores in the Masai Mara reserve and its surrounding humandominated pastoral ranches in Kenya. Biodivers Conserv 21:15091530

Boer WF, Vis MJP, Knegt HJ, Rowles C, Kohi EM, Langevelde FV, Pell M, Pretorius Y, Skidmore AK, Slotow R, Wieren SE, Prins HHT (2010) Spatial distribution of lions kills determined by the water dependency of prey species. J Mamm 91:1280-1286

Bommel LV, de Vaate MDB, Boer WFD, Iongh HHD (2007) Factors affecting livestock predation by lions in Cameroon. Afr J Ecol 45: 490-498

Butler JRA (2000) The economic costs of wildlife predation on livestock in Gokwe communal land, Zimbabwe. Afr J Ecol 38:23-30

Carbone C, Gittleman JL (2002) A common rule for the scaling of carnivore density. Sci 295:2273-2276

Carvalho EAR Jr, Zarco-Gonzáalez MM, Monroy-Vilchis O, Morato RG (2015) Modeling the risk of livestock depredation by jaguar along the Transamazon highway, Brazil. Basic Appl Ecol 16(5):413-419

Chavez PS (1996) Image-based atmospheric corrections revisited and improved. Photogramm Eng Remote Sens 62:1025-1036

Chellam R (1993) The ecology of Asiatic lion. Dissertation. Saurashtra University, Rajkot, India

Davis A, Goldman MJ (2019) Beyond payments for ecosystems services: considerations of trust, livelihoods and tenure security in community-based conservation projects. Oryx 53(3):491-496

Diamond F (2002) Evolution, consequences and future of plant and animal domestication. Nature 418:700-707

Davidson Z, Valeix M, Loveridge AJ, Hunt JE, Johnson PJ, Madzikanda H, Macdonald DW (2012) Environmental determinants of habitat and kill site selection in a large carnivore: scale matters. J Mammal 93 (3):677-685

Dormann CF, Elith J, Bacher S, Buchmann C, Carl G, Carré G, Marquéz JRG, Gruber B, Lafourcade B, Leitão PJ, Münkemüller T, McClean C, Osborne PE, Reineking B, Schröder, Skidmore AK, Zurell D, Lautenbach S (2013) Collinearity: a review of methods to deal with it and a simulation study evaluating their performance. Ecography 36:27-46

East R (1984) Rainfall, soil nutrient status and biomass of large African savanna mammals. Afr J Ecol 22:245-270

Elliott JP, Cowan IMCT, Holling CS (1977) Prey capture by the African lion. Can J Zool 55:1811-1828

ERDAS Inc (2015) Atlanta, Georgia

Fritts SH, Paul WJ (1989) Interactions of wolves and dogs in Minnesota. Wildl Soc B 17(2):121-123

Goldman MJ, de Pinho JR, Perry J (2010) Maintaining complex relations with large cats: Maasai and lions in Kenya and Tanzania. Hum Dimens Wildl 15:332-346

Goldman MJ, de Pinho JR, Perry J (2013) Beyond ritual and economics: Maasai lion hunting and conservation politics. Oryx 47(4):490-500

Hayward MW, Kerley GIH (2006) Prey preference of the lion (Panthera leo). J Zool 267(3):309-322

Hazzah L, Mulder MB, Frank LG (2009) Lions and warriors: social factors underlying declining African lion populations and the effect of incentive-based management in Kenya. Bio Conserv 142(11): $2428-2437$
Hazzah L, Dolrenry S, Naughton L, Edwards CTT, Mwebi O, Kearney F, Frank L (2014) Efficacy of two lion conservation programs in Maasailand, Kenya. Conserv Biol 28(3):851-860

Henschel P (2006) The lion in Gabon: historical records and notes on current status. Cat News 44:10-13

Hopcraft JGC, Sinclair ARE, Packer C (2005) Planning for success: Serengeti lions seek prey accessibility rather than abundance. J Anim Ecol 74:559-566

Ikanda DK, Packer C (2008) Ritual vs. retaliatory killing of African lions in the Ngorongoro conservation area, Tanzania. End Spec Res 6:6774

Inskip C, Zimmermann A (2009) Human-felid conflict: a review of patterns and priorities worldwide. Oryx 43:18-34

Kays RW, Patterson BD (2002) Mane variation in African lions and its social correlates. Can J Zool 80:471-478

Khorozyan I, Ghoddousi A, Soofi M, Waltert M (2015) Big cats kill more livestock when wild prey reaches a minimum threshold. Biol Conserv 192:268-275

Kiffner C, Nagar S, Kollmar C, Kioko J (2016) Wildlife species richness and densities in wildlife corridors of northern Tanzania. J Nat Conserv 31:29-37

Kissui BM (2008) Livestock predation by lions, leopards, spotted hyenas, and their vulnerability to retaliatory killing in the Maasai steppe, Tanzania. Anim Conserv 11:422-432

Kissui BM, Kiffner C, König HJ, Montgomery RA (2019) Patterns of livestocj depredation and cost-effectiveness of fortified livestock enclosures in northern Tanzania. Ecol Evol 9:11420-11433

Kolowski JM, Holekamp KE (2005) Spatial, temporal, and physical characteristics of livestock depredations by large carnivores along the Kenya reserve border. Biol Conserv 128:529-541

Koziarski A, Kissui B, Kiffner C (2016) Patterns and correlates of perceived conflict between humans and large carnivores in northern Tanzania. Biol Conserv 199:41-50

Kruuk H (2002) Hunter and hunted: relationships between carnivores and people. Cambridge University Press, New York, p 246

Kuiper T, Loveridge AJ, Parker DM, Johnson PJ, Hunt JE, Stapelkamp B, Sibanda L, Macdonald DW (2015) Seasonal herding practices influence predation on domestic stock by African lions along a protected area boundary. Bio Conserv 191:546-554

Laizer H, Tarimo TMC, Kissui B (2014) Home Range and Movement Patterns of Lions (Panthera Leo) in Tarangire National Park, Tanzania. Am J Res Commun 2(1):44-58

Lyngdoh S, Shrotriya S, Goyal SP, Clements H, Hayward MW, Habib B (2014) Prey preferences of the snow leopard (Panthera uncia): regional diet specificity holds global significance for conservation. PLoS One 9(2):1-12

Madden F (2004) Creating coexistence between humans and wildlife: global perspectives on local efforts to address human-wildlife conflict. Hum Dimens Wildl 9:247-257

Manly BFJ, McDonald LL, Thomas DL, McDonald TL, Erickson WP (2002) Resource selection by animals: statistical design and analysis for field studies. Springer Science Business Media, Dordrecht, p 222

Meena V, Jhala YV, Chellam R, Pathak BJ (2011) Implications of diet composition of Asiatic lions for their conservation. J Zool 284:60 67

Meriggi A, Lovari S (1996) A review of wolf predation in southern Europe: does the wolf prefer wild prey to livestock? J Appl Ecol 33:1561-1571

Michalski F, Boulhosa RLP, Faria A, Peres CA (2006) Human-wildlife conflicts in a fragmented Amazonian forest landscape: determinants of large felid depredation on livestock. Anim Conserv 9:179-188

Miller JRB, Jhala YV, Jena J, Schmitz OJ (2015) Landscape-scale accessibility of livestock to tigers: implications of spatial grain for modeling predation risk to mitigate human-carnivore conflict. Ecol Evol 5: 1354-1367 
Mishra C (2001) High altitude survival: conflicts between pastoralism and wildlife in the trans-Himalaya. Ph.D. dissertation. Wageningen University, Wageningen, The Netherlands

Mishra C, Prins HHT, VanWieren SE (2001) Overstocking in the transHimalayan rangelands of India. Environ Conserv 28:279-283

Mishra C, Allen P, McCarthy T, Madhusudan MD, Bayarjargal A, Prins HHT (2003) The role of incentive programs in conserving the snow leopard. Conserv Biol 17(6):1512-1520

Mizutani F (1999) Impact of leopards on a working ranch in Laikipia, Kenya. Afr J Ecol 37:211-225

Murdoch WW (1969) Switching in general predators: experiments on predator specificity and stability of prey populations. Ecol Monogr 39(4):335-354

Musiani M, Muhly T, Gates CC, Callaghan C, Smith ME, Tosoni E (2005) Seasonality and reoccurrence of depredation and wolf control in western North America. Wildl Soc B 33:876-887

Mwalyosi RBB (1992) Influence of livestock grazing on range condition in south-west Masailand, northern Tanzania. J Appl Ecol 29:581588

Nowell K, Jackson P (1996) Wild cats - status survey and conservation action plan. IUCN/ SSC Cat Specialist Group, Gland

O’Brien TG, Kinnaird MF, Wibisono HT (2003) Crouching tigers, hidden prey: Sumatran tiger and prey populations in a tropical forest landscape. Anim Conserv 6:131-139

Odden J, Herfindal I, Linnell JDC, Andersen R (2008) Vulnerability of domestic sheep to lynx depredation in relation to roe deer density. J Wildl Manag 72(1):276-282

Okello MM (2005) Land use changes and human-wildlife conflicts in the Amboseli area, Kenya. Hum Dimens Wildl 10(1):19-28

Olson ER, Ventura SJ, Zedler JB (2012) Merging geospatial and field data to predict the distribution and abundance of an exotic macrophyte in a large Wisconsin reservoir. Aquat Bot 96:31-41

Olson ER, Treves A, Wydeven AP, Ventura SJ (2014) Landscape predictors of wolf attacks on bear-hunting dogs in Wisconsin, USA. Wildl Res 41:584-597

Olson ER, Wydeven AP, Van Deelen TR, Ventura SJ, MacFarland D (2015a) Characterizing wolf-human conflict in Wisconsin, USA. Wildl Soc B 39:676-688. https://doi.org/10.1002/wsb.606

Olson ER, Stenglein JL, Shelley V, Rissman AR, Browne-Nuñez C, Voyles Z, Wydeven AP, Van Deelen TR (2015b) Pendulum swings in wolf management led to conflict, illegal kills, and a legislated wolf hunt. Conserv Lett 8(5):351-360

Olson ER, Van Deelen TR, Wydeven AP, Ruid DB, MacFarland DM, Ventura SJ (2019) A landscape of overlapping risks for wolf-human conflict in Wisconsin USA, J Environ Manage 248. doi: https://doi. org/10.1016/j.jenvman.2019.109307

Owen-Smith N, Mills MGL (2008) Shifting prey selection generates constrasting herbivore dynamics within a large-mammal predatorprey web. Ecology 89(4):1120-1133

Packer C, Pusey AE (1997) Divided we fall: cooperation among lions. Sci Am 22:79-100

Packer C, Scheel D, Pusey AE (1990) Why lions form groups: food is not enough. Am Nat 136:1-19

Packer C, Ikanda D, Kissui B, Kushnir H (2005) Lion attacks on humans in Tanzania: understanding the timing and distribution of attacks on rural communities will help to prevent them. Nature 436:927-928

Patterson BD, Kasiki SM, Selempo E, Kays RW (2004) Livestock predation by lions (Panthera leo) and other carnivores on ranches neighboring Tsavo National Parks, Kenya. Biol Conserv 119:507516

Pittiglio C, Skidmore AK, van Gils HAMJ, Prins HHT (2012) Identifying transit corridors for elephant using a long time-series. Int J Appl Earth Obs 14:61-72

Polisar J, Maxit I, Scognamillo D, Farrell L, Sunquist ME, Eisenberg JF (2003) Jaguars, pumas, their prey base, and cattle ranching: ecological interpretations of a management problem. Biol Conserv 109:297-310

Price EO (1984) Behavioral aspects of animal domestication. Q Rev Biol 59:1-32

Price EO (2002) Predation, infectious diseases and parasites. In: Price EO (ed) Animal domestication and behavior. CABI Publishing, New York, pp 107-112

R Development Core Team (2013) R: A language and environment for statistical computing. R Foundation for Statistical Computing, Vienna ISBN 3-900051-07-0, URL http://www.R-project.org

Riggio J, Jacobson A, Dollar L, Bauer H, Becker M, Dickman A, Funston P, Groom R, Henschel P, de Longh H, Lichtenfeld L, Pimm S (2013) The size of savannah Africa: a lion's (Panthera leo) view. Biodivers Conserv 22:17-35

Ripple WJ, Estes JA, Beschta RL, Wilmers CC, Ritchie EG, Hebblewhite M, Berger J, Elmhagen B, Letnic M, Nelson MP, Schmitz OJ, Smith DW, Wallach AD, Wirsing AJ (2014) Status and ecological effects of the world's largest carnivores. Science 343:6167

Ritchie ME, Olff H (1999) Spatial scaling laws yield a synthetic theory of biodiversity. Nature 400:557-560

Schaller GB (1972) Serengeti lion; a study of predator-prey relations. University of Chicago Press, Chicago

Scheel D (1993) Watching for lions in the grass: the usefulness of scanning and its effects during hunts. Anim Behav 46:695-704

Scheel D, Packer C (1991) Group hunting behavior of lions: a search for cooperation. Anim Behav 41:697-709

Schuette P, Creel S, Christianson D (2013) Coexistence of African lions, livestock, and people in a landscape with variable human land use and seasonal movements. Biol Conserv 157:148-154

Singh HS, Kamboj RD (1996) Predation pattern of the Asiatic lion on domestic livestock. Indian For 122:869-875

Stander PE (1992) Foraging dynamics of lions in a semi-arid environment. Can J Zool 70:8-21

Stander PE, Albon SD (1993) Hunting success of lions in a semi-arid environment. Symp Zool Soc Lond 65:127-143

Stoddart LC, Griffiths RE, Knowlton FF (2001) Coyote responses to changing jackrabbit abundance affect sheep predation. J Range Manag 54(1):15-20

Stokland JN, Halvorsen R, Stoa B (2011) Species distribution modeling: effect of design and sample size of pseudo-absence observations. Ecol Model 222:1800-1809

Sundararaj V, McLaren BE, Morris DW, Goyal SP (2012) Can rare positive interactions become common when large carnivores come livestock? Ecology 93:272-280

The Tanzania Land Conservation Trust (2011) Manyara trust land conservation area management plan, 2011-2021

Treves A, Karanth KU (2003) Human-carnivore conflict and perspectives on carnivore management worldwide. Conserv Biol 17:1491-1499

Valeix M, Loveridge AJ, Chamaillé-Jammes S, Davidson Z, Murindagomo F, Fritz H, Macdonald DW (2009) Behavioral adjustments of African herbivores to predation risk by lions: Spatiotemporal variations influence habitat use. Ecology 90 (1): 23-30

Valeix M, Hemson G, Loveridge AJ, Millis G, Macdonald DW (2012) Behavioural adjustments of a large carnivore to access secondary prey in a human-dominated landscape. J Appl Ecol 49:73-81

van Orsdol KG (1984) foraging behavior and hunting success of lions in queen Elizabeth National Park, Uganda. Afr J Ecol 22:79-100

Woodroffe R, Lindsey P, Romañach S, Stein A, ole Ranah SMK (2005) Livestock predation by endangered African wild dogs (Lycaon pictus) in northern Kenya. Biol Conserv 124:225-234

Publisher's note Springer Nature remains neutral with regard to jurisdictional claims in published maps and institutional affiliations. 
Predicting livestock depredation risk by African lions (Panthera leo) in a multi-use area of northern Tanzania

Beattie, K. ${ }^{\text {a, }}{ }^{*}$, Olson, E.R. ${ }^{\text {b }}$, Kissui, B. ${ }^{\mathrm{c}}$, Kirschbaum, A. $^{\mathrm{d}},{ }^{\&}$ Kiffner, C. ${ }^{\mathrm{c}}$

a. University of Connecticut, Storrs, Connecticut, USA

b. Northland College 1411 Ellis Avenue Ashland, Wisconsin, USA

c. School for Field Studies, Center for Wildlife Management Studies, PO Box 304 Karatu, Tanzania

d. National Park Service, Great Lakes Inventory and Monitoring Network, 2800 Lake Shore Drive East, Ashland, Wisconsin, USA

*Corresponding author: kristen.beattie@uconn.edu and 734-934-1132

In European Journal of Wildlife Research 
Online Resource 1 List of wild prey species of lions and wild non-prey observed on Manyara Ranch during the dry season (2014) based on Hayward and Kerley (2006)

Wild prey - Bushbuck (Tragelaphus scriptus), African buffalo (Syncerus caffer), Eland (Taurotragus oryx), Giraffe (Giraffa camelopardalis tippelskirchi), Grant’s gazelle (Gazella granti), Impala (Aepyceros melampus), Kirk's dik-dik (Madoqua kirkii), Lesser kudu (Tragelaphus imberbis), Steenbok (Raphicerus campestris), Thomson's gazelle (Gazella thomsonii), Warthog (Phacochoerus africanus), Waterbuck (Kobus ellipsipsiprymnus), Wildebeest (Connochaetes taurinus), Zebra (Equus quagga)

Wild non-prey - Aardvark (Orycteropus afer), Aardwolf (Proteles cristatus), African civet (Civettictis civetta), African wildcat (Felis libyca), Banded mongoose (Mungos mungo), Bat-eared fox (Otocyon megalotis), Black-backed jackal (Canis mesomelas), Dwarf mongoose (Helogale parvula), Elephant (Loxodonta aafricana), Common genet (Genetta genetta), Ground hornbill (Bucorvus leadbeateri), Helmeted guineafowl (Numida meleagris), Cape hare (Lepus capensis), Honey badger (Mellivora capepensis), Lion (Panthera leo), Olive baboon (Papio cynocephalus anubis), Ostrich (Struthio camelus), Porcupine (Hystrix cristata), Secretary bird (Sagittarius serpentarius), Spotted hyena (Crocuta crocuta), Striped hyena (Hyaena hyaena), Vervet monkey (Cercopithecus aethiops), White-tailed mongoose (Ichneumia albicauda), Zorilla (Ictonyx striatus) 
Online Resource 2 Wild mammal species richness, predator, wild prey, and livestock events, events per trap night, and observed individuals at camera sites in Manyara Ranch, Tanzania

\begin{tabular}{|c|c|c|c|c|c|c|c|c|c|c|c|c|}
\hline \multirow{2}{*}{$\begin{array}{c}\text { Camera } \\
\text { Site }\end{array}$} & \multicolumn{3}{|c|}{ Wild Prey } & \multicolumn{3}{|c|}{ Livestock } & \multicolumn{3}{|c|}{ Predators } & \multicolumn{3}{|c|}{ Species Richness } \\
\hline & $\begin{array}{c}\text { Total } \\
\text { Events }\end{array}$ & $\begin{array}{c}\text { Total } \\
\text { Observed }\end{array}$ & $\begin{array}{c}\text { Events } \\
\text { /TN }\end{array}$ & $\begin{array}{c}\text { Total } \\
\text { Events }\end{array}$ & $\begin{array}{c}\text { Total } \\
\text { Observed }\end{array}$ & $\begin{array}{c}\text { Event } \\
\text { s/TN }\end{array}$ & $\begin{array}{c}\text { Total } \\
\text { Events }\end{array}$ & $\begin{array}{c}\text { Total } \\
\text { Observed }\end{array}$ & $\begin{array}{c}\text { Events/ } \\
\text { TN }\end{array}$ & $\begin{array}{c}\text { Total } \\
\text { Events }\end{array}$ & $\begin{array}{l}\text { Total } \\
\text { Obs. }\end{array}$ & $\begin{array}{c}\text { Events/ } \\
\text { TN }\end{array}$ \\
\hline 1 & 56 & 97 & 1.14 & 9 & 145 & 0.18 & 14 & 16 & 0.29 & 128 & 19 & 0.39 \\
\hline 3 & 81 & 221 & 1.65 & 6 & 103 & 0.12 & 1 & 1 & 0.02 & 131 & 21 & 0.43 \\
\hline 4 & 23 & 51 & 0.47 & 24 & 886 & 0.49 & 6 & 6 & 0.12 & 106 & 19 & 0.39 \\
\hline 7 & 44 & 57 & 1.33 & 34 & 840 & 1.03 & 3 & 5 & 0.09 & 130 & 22 & 0.67 \\
\hline 11 & 103 & 260 & 2.10 & 16 & 428 & 0.33 & 1 & 5 & 0.02 & 159 & 20 & 0.41 \\
\hline 12 & 22 & 46 & 0.45 & 133 & 6,561 & 2.71 & 1 & 2 & 0.02 & 350 & 18 & 0.37 \\
\hline $\mathrm{C}$ & 25 & 76 & 1.47 & 8 & 347 & 0.47 & 0 & 0 & 0.00 & 54 & 8 & 0.47 \\
\hline $\mathrm{E}$ & 15 & 94 & 0.88 & 1 & 26 & 0.06 & 4 & 5 & 0.24 & 31 & 11 & 0.65 \\
\hline $\mathrm{F}$ & 3 & 4 & 0.19 & 16 & 609 & 1.00 & 1 & 1 & 0.06 & 33 & 8 & 0.50 \\
\hline $\mathrm{G}$ & 13 & 55 & 0.81 & 18 & 451 & 1.13 & 0 & 0 & 0.00 & 53 & 10 & 0.62 \\
\hline $\mathrm{H}$ & 5 & 20 & 0.29 & 9 & 329 & 0.53 & 0 & 0 & 0.00 & 21 & 8 & 0.47 \\
\hline I & 10 & 20 & 0.59 & 15 & 229 & 0.88 & 0 & 0 & 0.00 & 39 & 11 & 0.65 \\
\hline $\mathrm{J}$ & 13 & 37 & 0.81 & 7 & 255 & 0.44 & 0 & 0 & 0.00 & 26 & 10 & 0.62 \\
\hline $\mathrm{K}$ & 30 & 63 & 1.88 & 3 & 132 & 0.19 & 2 & 2 & 0.13 & 59 & 21 & 1.31 \\
\hline $\mathrm{L}$ & 5 & 18 & 0.31 & 8 & 750 & 0.50 & 0 & 0 & 0.00 & 31 & 10 & 0.62 \\
\hline $\mathrm{M}$ & 19 & 98 & 1.19 & 13 & 470 & 0.81 & 1 & 1 & 0.06 & 48 & 11 & 0.69 \\
\hline $\mathrm{N}$ & 1 & 1 & 0.06 & 3 & 20 & 0.19 & 0 & 0 & 0.00 & 6 & 4 & 0.25 \\
\hline $\mathrm{P}$ & 2 & 4 & 0.13 & 10 & 395 & 0.63 & 0 & 0 & 0.00 & 26 & 9 & 0.56 \\
\hline Q & 14 & 28 & 0.88 & 7 & 308 & 0.44 & 0 & 0 & 0.00 & 30 & 6 & 0.38 \\
\hline $\mathrm{R}$ & 3 & 3 & 0.19 & 0 & 0 & 0.00 & 0 & 0 & 0.00 & 7 & 4 & 0.25 \\
\hline $\mathrm{S}$ & 34 & 70 & 2.12 & 9 & 334 & 0.56 & 3 & 3 & 0.19 & 84 & 19 & 1.19 \\
\hline $\mathrm{T}$ & 8 & 9 & 0.5 & 10 & 101 & 0.63 & 1 & 1 & 0.06 & 29 & 10 & 0.62 \\
\hline $\mathrm{U}$ & 4 & 4 & 0.25 & 8 & 142 & 0.50 & 2 & 2 & 0.13 & 38 & 10 & 0.62 \\
\hline $\mathrm{V}$ & 5 & 22 & 0.31 & 1 & 19 & 0.06 & 2 & 3 & 0.13 & 20 & 10 & 0.62 \\
\hline
\end{tabular}


Online Resource 3 Model averaged coefficients, standard errors, and p-values for estimating the likelihood of livestock depredation year-round by lions on Manyara Ranch, Tanzania using ecological and geospatial variables

\begin{tabular}{llll}
\hline Coefficients & Estimate & Standard Error & $\boldsymbol{p}$-value \\
\hline Intercept & -29.774 & 14.021 & $0.0337^{*}$ \\
Mean NDVI & 134.063 & 66.277 & $0.0431^{*}$ \\
Wild Prey & 1.638 & 1.024 & 0.1097 \\
\hline
\end{tabular}


Online Resource 4 Sample-size corrected Akaike Information Criterion scores $\left(\mathrm{AIC}_{\mathrm{c}}\right), \Delta \mathrm{AIC}_{\mathrm{c}}$, and model weights of logistic regression models predicting livestock depredation risk by African lions year-round (All year), during the dry season (Dry), and during the wet season (Wet) for Manyara ranch, northern Tanzania

\begin{tabular}{|c|c|c|c|c|c|c|c|c|c|}
\hline & All year & & & Dry & & & Wet & & \\
\hline Model & $\mathrm{AIC}_{\mathrm{c}}$ & $\Delta \mathrm{AIC}_{\mathrm{c}}$ & Weight & $\mathrm{AIC}_{\mathrm{c}}$ & $\Delta \mathrm{AIC}_{\mathrm{c}}$ & Weight & $\mathrm{AIC}_{\mathrm{c}}$ & $\Delta \mathrm{AIC}_{\mathrm{c}}$ & Weight \\
\hline $\begin{array}{l}\text { NDVI * Dist. } \\
\text { Water }\end{array}$ & 130.97 & 0.00 & 0.20 & 91.83 & 0.00 & 0.48 & 65.98 & 5.23 & 0.02 \\
\hline $\begin{array}{l}\text { Dist. Boma }+ \\
\text { NDVI * Dist. } \\
\text { Water }\end{array}$ & 131.06 & 0.09 & 0.19 & 93.53 & 1.70 & 0.20 & 64.73 & 3.97 & 0.03 \\
\hline $\begin{array}{l}\text { NDVI + Dist. } \\
\text { Boma * Dist. } \\
\text { Water }\end{array}$ & 131.17 & 0.20 & 0.18 & 97.69 & 5.86 & 0.03 & 61.46 & 0.71 & 0.18 \\
\hline $\begin{array}{l}\text { Dist. Water + } \\
\text { Dist. Boma * } \\
\text { NDVI }\end{array}$ & 131.35 & 0.38 & 0.17 & 95.06 & 3.23 & 0.09 & 64.71 & 3.96 & 0.03 \\
\hline $\begin{array}{l}\text { NDVI + Dist. } \\
\text { Water }\end{array}$ & 131.56 & 0.59 & 0.15 & 94.46 & 2.63 & 0.13 & 63.95 & 3.19 & 0.05 \\
\hline $\begin{array}{l}\text { Dist. Boma * } \\
\text { Dist. Water }\end{array}$ & 133.18 & 2.21 & 0.07 & 98.59 & 6.76 & 0.02 & 60.75 & 0.00 & 0.25 \\
\hline Dist. Water & 134.63 & 3.66 & 0.03 & 97.13 & 5.29 & 0.03 & 62.63 & 1.88 & 0.10 \\
\hline $\begin{array}{l}\text { Dist. Boma + } \\
\text { Dist. Water }\end{array}$ & 136.66 & 5.69 & 0.01 & 98.44 & 6.60 & 0.02 & 62.83 & 2.08 & 0.09 \\
\hline$N D V I$ & 142.76 & 11.79 & 0.00 & 104.08 & 12.24 & 0.00 & 64.62 & 3.86 & 0.04 \\
\hline $\begin{array}{l}\text { Dist. Boma + } \\
\text { NDVI }\end{array}$ & 143.76 & 12.79 & 0.00 & 106.10 & 14.26 & 0.00 & 63.61 & 2.86 & 0.06 \\
\hline $\begin{array}{l}\text { Dist. Boma * } \\
\text { NDVI }\end{array}$ & 144.00 & 13.03 & 0.00 & 106.14 & 14.31 & 0.00 & 65.65 & 4.90 & 0.02 \\
\hline Null & 146.74 & 15.77 & 0.00 & 108.04 & 16.20 & 0.00 & 63.24 & 2.49 & 0.07 \\
\hline Dist. Boma & 148.56 & 17.59 & 0.00 & 108.47 & 16.63 & 0.00 & 63.81 & 3.06 & 0.05 \\
\hline
\end{tabular}

